\title{
LEGAL CLINIC AS A FACTOR OF LAWYER'S EMOTIONAL INTELLIGENCE AND PROFESSIONAL ETHICS DEVELOPMENT
}

\author{
Andrii M. Kuchuk ${ }^{1}$ \\ Bohdan I. Andrusyshyn ${ }^{2}$ \\ Yevhen V. Bilozorov ${ }^{3}$ \\ Olha V. Minchenko ${ }^{4}$ \\ Liudmyla A. Filianina ${ }^{5}$
}

\begin{abstract}
The urgency of the research is stipulated by the necessity to critically reflect on functioning of an innovative form of legal education - a legal clinic in order to determine the possibility of clinical education to be a factor in the development of students' emotional intelligence and professional ethics. The purpose of the article is to systematically cover the possible positive and negative aspects of the widespread introduction of legal clinic as a means of individual students' qualities development into law education. The study is based on the method of systematic analysis, allowing comprehensively cover legal clinics functions and critically evaluate the impact of legal clinics on emotional intelligence and professional ethics of
\end{abstract}

future lawyers' development. The article shows that legal clinic, being an innovative form of legal education aimed at developing practical skills of future lawyers, performs both educational and social functions. Legal clinic promotes the development of emotional intelligence (allowing students to better understand and control their emotion, as well as to adequately perceive the client's psychological state, choosing appropriate tactics of behavior) and professional ethics (understanding the importance of the principle of the rule of law, the priority of human rights, awareness of the role of a lawyer in society and the importance of pro bono activities). Article materials can be used for further study of legal clinics impact

Sumy State Pedagogical University, Romenska Street, 87, Sumy, 40002, Ukraine. E-mail: ${ }^{1}$ kuchuk.a@ust-hk.com.cn

National Pedagogical Dragomanov University, Pyrogov Street, 9, Kyiv, 01601, Ukraine ${ }^{2}$

National Academy of Internal Affairs, Solomianska Square, 1, Kyiv, 03035, Ukraine ${ }^{3}$

National Academy of Internal Affairs, Solomianska Square, 1, Kyiv, 03035, Ukraine ${ }^{4}$

University of Customs and Finance, V. Vernadskyi Street, 2/4, Dnipro, 49000, Ukraine ${ }^{5}$ 
on the future law practitioners' individual qualities development, and can also be the benchmarks for improving the legal clinical education.

Keywords: emotional intelligence, legal clinic, professional ethics, the rule of law, educational process.

\section{Introduction}

At the beginning of the second half of the twentieth century, the peoples of the United Nations recognized the universality of human rights, proclaiming human dignity, democracy, the rule of law and human rights as values. This stipulated urgency of the issue of implementation of these values into the national legislation of participants of international cooperation, which has not decreased at the beginning of the third millennium. Appreciating the significance of the Universal Declaration of Human Rights (1948), G. Brown (2016) regards it as a "common conscience" for humanity, a call to the establishment of a high standard of living for humanity. Constantly, reports of various international organizations (both governmental and non-governmental) point to the problems of human rights, democracy, publicity, and freedom on
42

the NET provision. This problem is emphasized by Z.R. Al Hussein (2018), K.R. Carriere (2019), A. Clemence, T. Devos \& W. Doise (Clemence et al., 2001).

This necessitates change in public policy in the legal field. Public authorities should proceed from the recognition of human rights and their obligation to provide human rights. Civil society and independent courts play the key role in improving the performance of the state's activities (in terms of human rights provision). Therefore, any democratic state, any civil society is interested in the existence of the effective remedies and institutions for the protection of human rights, the presence of lawyers properly performing their social role. That is why legal education will always be an important issue in any democratic society, which enables to prepare lawyers for whom human dignity and human rights are the fundamental values. This issue is especially relevant for the post-soviet states that have chosen the European vector of development. At the same time, for them, as well as for the states where a high level of human rights is consistently secured, the problem of particular means of improving legal 
education is important. Some aspects of legal education improving are always in the spotlight of scientists (Bilozorov et al., 2019).

In this context, it should be noted that since the end of the twentieth century, legal clinics as a means of improving legal education or innovative forms of education study has become relevant. This is mainly the study the following states as Poland, Russia, Ukraine, and the United States of America. This is connected with the establishment of the first legal clinics. "1st October 1997 the first legal clinic at the Jagiellonian University was opened, at the same time being the first legal clinic in Cracow, 3 and first successful legal clinic in Central and Eastern Europe" (Mamak et al., 2018). However, the issue of the legal clinic as a means of developing individual abilities and qualities of a lawyer remains unresolved.

Therefore, the purpose of this study is to systematically clear up both possible positive and negative aspects of the widespread adoption of legal clinics into legal education as a means of emotional intelligence and professional ethics developing. Method of systematic analysis allowing comprehensively cover legal clinics functions and critically evaluate the impact of legal clinics on the emotional intelligence and professional ethics of future lawyers' development lie in the basis of the study.

\section{Justification of the Need for Functioning of Legal Clinics}

The most researched are the following legal clinics aspects:

- assistance of legal clinics in further employment of students (Blandy, 2019); - legal clinic as a factor of development of communicative qualities of students (Meshcheryakova and Petrushin, 2013); - legal clinic as an element of modernization of legal education (Khudoykina and Lysenko, 2017);

- legal clinic as an innovative form of students' education (Khudoykina and Lysenko, 2014);

- functions of legal clinics (Anokhina and Eliseeva, 2018);

- legal clinic as a special variety of legal education (Dobroboh et al., 2019).

Their common drawback is paying attention to certain positive aspects of legal clinics functioning. However, the complex and critical analysis of this relatively new law institute, as well as the lack of coverage of the students' following qualities 
development such as emotional intelligence and culture of behavior stay out of sight. In the conditions of society functioning on the principles of the rule of law and democracy, respect for human rights and human dignity, there is a necessity for legal education permanent improvement, and its innovative forms development. This stipulates the importance of systematic analysis of the introduction of legal clinical education, critical reflection on its positive impact on the formation of students' practical skills and formation of the qualities that are important for effective legal activity.

The main functions of legal clinics are educational and social ones. It is within the scope of these functions that students' emotional intelligence can be developed, which will enable them to adequately understand their emotions and the client's psychological state, to effectively use this knowledge to solve professional challenges, prevent fatigue and depression. Excessive empathy on the part of the lawyer can be a factor in making inadequate decisions. The provision of legal assistance within a legal clinic helps students to understand law not as a prescriptive piece of legislation, but as a living, dynamic phenomenon allowing students to better
44 understand the essence of the rule of law. Working with socially unprotected groups contributes to an awareness of the social role of lawyers, and to understanding the importance of pro bono activities.

The culture of behavior with clients, promotion of the rule of law and human rights, respect for human dignity, understanding of the essence and public purpose of the legal profession are all components of the professional ethics of a lawyer. Understanding the importance for the legal activity of possessing by a lawyer of high emotional intelligence and adherence to professional ethics should be a benchmark for developing a "road map" for improving legal education.

Is a legal clinic indeed a form of legal education that facilitates training of law professionals who can perform the functions entrusted to them by society, and promotes the development of the emotional intelligence and professional ethics of the lawyer? The answer to this question involves an analysis of the functions of legal clinics. First, it is generally recognized in the legal education midst that legal clinics have an educational function. Of course, legal clinics are created within higher 
educational institutions, they are an element of the educational process, direct participants in clinical activities are students of higher educational institutions, and so legal clinics function precisely within the educational process to improve the practical training of students, and to develop certain skills and qualities. Are legal clinics indeed the form of training that can help develop practical skills and qualities? Answering this question, one should clearly understand the content of the student's activities in the legal clinic. The main forms of students' activities in the legal clinic (in the context of educational function) are:

1) providing verbal and written advice to clients;

2) drafting of legal documents (application, petition, statement, complaint, official letter);

3 ) in some cases, representation of the client in the authorities (if it is provided by national legislation).

In any of the abovementioned cases, the student should:

1. Familiarize himself/herself with the circumstances of the client's case, find out all the information important for resolving a legal conflict.
45

The accomplishment of this task contributes to the formation of communication skills with clients, conducting professional interviews, interviews; and the skills necessary for legal analysis are formed.

2. Solving a specific situation, the student examines the legislation that regulates the relevant social relations. In addition, quite often the student is faced with the lack of theoretical knowledge to solve the client's problem, which promotes him/her to search for an answer independently, to study additional literature, case law, both national and international, such as the practice of the European Court of Human Rights. It is pertinent to note that the judges of the European Court of Human Rights also apply the legal doctrine of the United States of America. For example, in a dissenting opinion, in the Case of Svetina v. Slovenia Judge Pinto de Albuquerque argues for the inadmissibility of evidence and mentions the American concepts of the "independent source" formulated in the case Silverthorne Lumber Co. v. United States and the "purified spot" formulated in the case Nardone v. United States, as well as emphasizes the doctrine of "inevitable discovery" formulated by the 
Supreme Court of the United States in Nix v. Williams (Case of Svetina v. Slovenia, 2018). In doing so, the student learns the substantive and procedural norms in correlation, interconnected skills, which are not limited to one of subjects are formed. Skills are shaped in the opposite direction (compared to classical forms of legal education): from practice to theory. Therefore, solving this problem contributes to the formation of stable knowledge of the effects of legal rules in specific life situations; activates the search activity of the student, and promotes the formation of skills of legal analysis, critical thinking.

\section{The Role of Legal Clinics in the} Formation of Lawyers' Emotional Intelligence

In our opinion, more important fact in using a legal clinic as a form of legal education is that that a student works with a person. This contributes to the development of emotional intelligence, which is an important factor in a successful career under present-day conditions. "Individuals with high level of emotional intelligence possess marked abilities to understand their own emotions and other people's emotions, as well as to manage the emotional sphere,
46

which leads to greater adaptability and effectiveness in communication" - noted N. Yarosh, and V. Artiukhova (Yarosh and Artiukhova, 2019). Emotional intelligence for a lawyer is the means that allows to establish contact with the client, make a considered decision, adequately perceive own emotional state. After all, lawyer's client is usually in an unusual situation for him; mostly conflict one, which is a factor of his emotionality, aggression, feeling of hopelessness, anger, and irritability. Excessive empathy on the part of a lawyer can be the factor in making inappropriate decisions, especially when it comes to a student providing legal assistance within a legal clinic. Moreover, student's constant being in a state of strong empathy cannot but affect his psychological state, in particular, in the form of exhaustion, fatigue.

In addition, the client does not always understand what he or she needs, so the developed emotional intelligence allows the lawyer to establish interaction with his client and develop the right strategy taking into account the client's needs and being based on the provisions of the law.

Due to the fact that socially disadvantaged people are clients of legal 
clinics, as the experience of authors and the students of legal clinics shows, quite often clients seek not only legal aid, what is important for them is that they are heard. In this context, one may but partially disagree with R. Kant, who researched students' emotional intelligence and concluded that students of School of Education possess emotional intelligence higher than the emotional intelligence of students of Law \& Governance. At the same time, in his opinion, students studying for a lawyer should not have to show their emotions, since this is not peculiar to their profession (Kant, 2019). Indeed, lawyers should objectively resolve legal conflicts without excessive emotion, but emotional intelligence itself requires the ability to properly understand and manage their emotions, as well as to understand the client's emotional state. The absence of any emotion in the solving family matters related to the decision of the fate of the child, criminal cases involving the murder of a number of persons or sexual crimes is unlikely to have a positive impact on building trust with a client who is a victim. People with high emotional intelligence "can better motivate themselves and others, are more active, innovative and creative, effective leaders, work better under stress and cope with changes, are more in tune with themselves" (Barko et al., 2019).

Of particular importance, in our view, is that that emotional intelligence can be a factor of a lawyer's competitiveness in the future. The point is that in the conditions of digitization of law, the use of information technology under the legal business, including bots for consulting, contract analysis, the skills such as making unique decisions, understanding clients' needs, effective dialogue and mediation will help a lawyer to be an active participant in the market of legal services. The possible negative psychological impact of legal clinics' clients on students because of excessive empathy of the latter should also be viewed as a positive influence of the legal clinic, as the student may evaluate his or her options and decide to change the profession or the necessity to attend additional courses or choose the appropriate subjects of psychological direction that will help to generate high level of emotional intelligence.

In addition, an important positive aspect of the functioning of legal clinics within higher educational institutions is the formation of students' 
understanding of law not as a prescriptive piece of legislation, but as a living, dynamic, and social and cultural phenomenon. The student should be aware that the prescriptions of the legislation are abstract and law is concrete. This approach allows students to better understand the essence of the rule of law. While solving the problems of clients of a legal clinic, students may encounter such violations as of the principle of legal certainty, the principle of proportionality (which is directly related to the rule of law). And it will also help to realize the importance of implementing the rule of law. We can emphasize that within the Western legal culture, legal values are human dignity, human rights, the rule of law, democracy. This is why legal education in European states, the United States of America, aims to train lawyers who:

- affirm the rule of law in society, - protect human rights,

- abide by the rules of professional ethics,

- are aware of the social role of the legal profession.

Therefore, it is possible to agree with P. Yanchenko on the importance in the current context of the high legal consciousness of future lawyers, who should become "an expert on the consciousness, morality of citizens, their ability to correct behavior, educator and facilitator in difficult life situations" (Yanchenko, 2018). This is especially crucial for future lawyers in the postsoviet states, including Ukraine. For whom human rights and the rule of law "have not become the part of the national mentality (including the representatives of the political elite) and the style of thinking (even of most members of the legal profession)" (Koziubra, 2017).

The only downside to implementing clinical education is the organizational questions to solve. However, this shortcoming does not concern the educational activities of students, but the additional attraction of funds by higher educational institutions. Legal clinic functioning requires the presence of employees - the head of the legal clinic, the deputy (assistant) director of the legal clinic (these may be separate positions at the higher educational institution). Lecturers involved in legal clinic activities spend extra time helping students, training for them etc. Usually, such work is not paid or included into the obligatory full time job of a lecturer. In addition, functioning 
of the legal clinic requires premises where the reception clients will be held. Crucial organizational aspect that needs to be solved is the students' schedule: how does a legal clinic work load will be enrolled into that schedule? Is it a substantive work? Or is it probation?

Thus, given that such classical forms of studying as lectures, seminars, final control are quite outdated, it can be argued that legal clinic is indeed an important interactive form of legal education that allows to effectively forming the skills of professional legal activity. A critical analysis of the legal clinic's educational function makes it possible to identify only the positive aspects of clinical education for students. The only drawback of introducing legal clinics is the challenge of effective organization of legal clinic activities. Second, it is generally recognized in the legal educational environment that legal clinics have a social function. Usually socially vulnerable groups are the clients of legal clinics. For example, according to the legislation of Ukraine, the purpose of a legal clinic is to "provide access to legal aid for representatives of socially vulnerable groups of society", "to provide free legal advice to citizens of socially vulnerable sections of society
(Typical provision for a legal clinic..., 2006).

Legal aid in legal clinics is provided free of charge, which is an important means of legal protection of the population, especially of those who cannot pay for such services. It should be emphasized that the free legal aid of legal clinics and the fact that assistance is provided by students are not the factors of inadequate legal assistance. The students participating in the legal clinic are committed to constantly improve their level of knowledge, conscientiously fulfill their obligations, and provide the client with all the necessary information. It should also be noted that generally clients resort legal clinic with not complex legal situations that are typical. In addition, the client will not receive counseling or other legal assistance without checking the student's work by a lecturer who is usually a practicing lawyer or has previously practiced law. Therefore, the client will receive qualified legal assistance.

In this context, it is worth noting one problem that we mentioned above. The work of lecturers and students in a legal clinic is generally not paid and not included into the teaching full time job. That is it is additional work 
of the lecturer. Therefore, the activities of legal clinics face the following challenges: financing of legal clinics and remuneration of the clinic staff, lecturers involved in the clinic activities; lack of qualified lecturers who can and want to provide students with practical skills (Khudoykina and Lysenko, 2017). However, in our opinion, this problem is partly financial, and partly ethical. For example, there are cases related to the involvement of legal practitioners in free labor connected with promoting people in the promotion of human rights implementation in the practice of the European Court of Human Rights under Art. 4 (Prohibition of slavery and forced labor) The Convention for the Protection of Human Rights and Fundamental Freedoms, The European Court of Human Rights, for example, did not admit to forced labor the following:

- in the Van der Mussele case appointment of a lawyer to defend the indigent free of charge (Case of Van der Mussele..., 1983),

- in the case of Bucha v. Slovakia appointment of a lawyer to protect his client free of charge (Case of Bucha v. Slovakia, 2011),

- in the case of Graziani-Weiss v. Austria - appointment of a lawyer as guardian (Case of Graziani-Weiss v. Austria, 2011),

- in the case of X. v. Germany - notary work for non-commercial organization for a lesser profit (Case of X. v. Germany, 1979).

Herewith the Court considered the performance of certain work by lawyers as such, which forms a part of normal civic obligations, and also took into account that such work did not go beyond their normal activities and that lawyers had certain advantages over other persons (eg, the exclusive right to defend a person in court) (Case of Van der Mussele..., 1983). In our opinion, the educational activities of lecturers with students in a legal clinic also do not go beyond the normal activities of the lecturer and can be considered as such which form a part of normal civic obligations and do not impose a disproportionate obligation on the lecturer.

Although participation of students in pro bono during professional training does not increase the likelihood of further participation in such activities after graduation (McKeown, 2015), studying in a legal clinic influences the awareness of the role of the lawyer in 
society and the formation of ethical behavior skills. V. C. Burbano, J. Mamer, and J. Snyder having analyzed the activities of the top 200 law firms, argue that "pro bono activities can benefit firms through human capital learning and screening mechanisms, given the stretch roles that pro bono engagements allow" (Burbano et al., 2018).

\section{Conclusions}

Legal clinic, being an innovative form of legal education aimed at developing the practical skills of future lawyers, performs both educational and social functions. Performing these functions, the legal clinic promotes the development of emotional intelligence, which allows students to better understand their emotions and control them, as well as adequately perceive the client's psychological state, choosing appropriate behaviour tactics and professional ethics - understanding the importance of the rule of law, the priority of human rights, priority of human rights, understanding the role of a lawyer in the community and the importance of pro bono activities.
1. The importance of legal clinics for improving the practical training of students makes it possible to conclude the importance of further implementation of clinical activities within higher educational institutions.

2. The importance of the development of emotional intelligence, understanding the importance of the rule of law, awareness of the role of the lawyer in society should become the benchmarks for improving clinical education.

3. The results obtained may form the basis for further studies of the impact of the legal clinic on the development of students' emotional intelligence, as well as the formation of ethical attitudes of future lawyers.

\section{References:}

Al Hussein ZR. (2018). Opening statement and global update of human rights concerns by UN High Commissioner for Human Rights. https://www.ohchr.org/EN/NewsEvents/ Pages/DisplayNews.aspx?NewsID=232 $\underline{06 \& \text { Lang ID }=\mathrm{E}}$.

Anokhina OV, Eliseeva GV. (2018). On the role of the legal clinic in the future 
lawyers' activities of. Bulletin of the Siberian Institute of Business and Information Technology, 1(25), 89-94.

Barko VI, Ostapovych VP, Oleshko PS. (2019). Ukrainian-language adaptation of questionnaire of level and structure of emotional intelligence for psychological selection of police officers. Psychological Journal, 3(23), 9-25. DOI: 10.31108/1.2019.3.23.1.

Bilozorov IV, Ivanii OM, Perepolkin SM. (2019). International customs law as a means of public and private law specialists training improvement. The Asian International Journal of Life Sciences, 21(2), 433-446.

Blandy S. (2019). Enhancing employability through student engagement in pro bono projects. International Journal of Clinical Legal Education, 26(1), 7-45. DOI: 10.19164/ijcle.v26i1.821.

Brown G. (2016). The Universal Declaration of Human Rights in the 21st century: a living document in a changing world. Cambridge: Open Book Publishers. DOI: 10.11647/OBP.0091.
Burbano VC, Mamer J, Snyder J. (2018).

Pro bono as a human capital learning and screening mechanism: Evidence from law firms. Strategic Management, 39(11), 2899-2920. DOI: 10.1002/smj.2947.

Carriere KR. (2019). Threats to human rights: a general review. Journal of Social and Political Psychology, 7(1), 832.

Clemence A, Devos T, Doise W. (2001). Social representations of human rights violations: Further evidence. Swiss Journal of Psychology, 60(2), 89-98. DOI: 10.1024//1421-0185.60.2.89.

Dobroboh L, Zavhorodnii V, Orlova O. (2019). Legal education in Ukraine in the context of integration to the European educational space. The Asian International Journal of Life Science, 21(2), 421-432.

Case of Van der Mussele v. Belgium (Application no. 8919/80). (1983). European Court of Human Rights. http://hudoc.echr.coe.int/eng?i=00157591. 
Case of Svetina v. Slovenia (Application no. 54335/14). (2018). Concurring Opinion of Judge Pinto de Albuquerque. European Court of Human Rights. http://hudoc.echr.coe.int/eng?i=001183124.

Case of X. v. Germany (Application no. 8410/78). (1979). European Court of Human Rights. http://hudoc.echr.coe.int/eng?i=00174052.

Case of Bucha v. Slovakia (Application no. 43259/07). (2011). European Court of Human Rights. http://hudoc.echr.coe.int/eng?i=001106599.

Case of Graziani-Weiss v. Austria (Application no. 31950/06). (2011). European Court of Human Rights. http://hudoc.echr.coe.int/eng?i=001107022.

Kant R. (2019). Emotional intelligence: A study on university students. Journal of Education and Learning, 13(4), 441446.

DOI:

10.11591/edulearn.v13i4.13592.
Khudoykina TV, Lysenko VV. (2014). Legal clinic as an innovative form of law students training. Integration of Education, 1(74), 19-24.

Khudoykina TV, Lysenko VV. (2017). Development of clinical legal studies as an essential component in the modernization of legal education. Integration of Education, 21(1), 124137. DOI: $\quad 10.15507 / 1991-$ 9468.086.021.201701.124-137.

Koziubra M. (2017). The rule of law, human rights and local self-government: certain interconnecting issues. Scientific notes of the National University "KyivMohyla Academy", 200, 67-71.

Mamak K, Kowalska KJ, Milan E, Modrzewski PKAF. (2018). The past, present and future of clinical legal education in Poland. International Journal of Clinical Legal Education, $25(2)$, 89-121.

DOI: 10.19164/ijcle.v25i2.723.

McKeown P. (2015). Law student attitudes towards pro bono and voluntary work: The experience at Northumbria University. International Journal of 
Clinical Legal Education, 22(1), 6-46.

DOI: 10.19164/ijcle.v22i1.407.

Meshcheryakova EI, Petrushin AI. (2013). Training in legal clinic and law students' communicative competence development. Siberian Psychological Journal, 49, 59-64.

Typical provision for a legal clinic of a higher educational institution of Ukraine. (2006). https://zakon.rada.gov.ua/laws/show/z0 956-06.

Universal Declaration of Human Rights. (1948). United Nations. https://www.un.org/en/universaldeclaration-human-rights/.

Yanchenko P. (2018). Structural and Functional Model of formation of Future Lawyers' Legal Culture in the process of professional training. Pedagogical Sciences, 71, 47-53.

Yarosh N, Artiukhova V. (2019). Correlation between the concepts of emotional intelligence and sanogenic thinking of personality. Psychological Journal, 5(6), 122-133. DOI: 10.31108/1.2019.5.6.9 